\title{
A circadian rhythm in lipid mobilization which is altered in IDDM
}

\author{
E . H agström-Toft ${ }^{1}$, J. B olinder ${ }^{1}$, U . U ngerstedt ${ }^{2}$, P. A rner ${ }^{1}$ \\ ${ }^{1}$ Department of Medicine and Research Center, Huddinge Hospital, Huddinge, Sweden \\ ${ }^{2}$ Department of Pharmacology, Karolinska Institute, Stockholm, Sweden
}

Summary It is not clear how circadian lipolysis and circulating concentrations of non-esterified fatty acids (NEFA) are altered in intensively treated insulindependent diabetic (IDDM) patients. Ten IDDM patients on an intensive insulin regimen and eight healthy control subjects were investigated under ordinary living conditions for $27 \mathrm{~h}$ by microdialysis of subcutaneous adipose tissue. The true tissue glycerol concentration and adipose blood flow changes were monitored as an index of lipolysis. A circadian pattern in adipose tissue lipolysis was observed in both groups, decreasing during the day and increasing during evening-night. The daytime decrease was normal, but the evening-night rise was elevated in IDDM $(p=0.03)$. Circulating NEFA decreased during the day and increased at night. The latter increase was enhanced threefold in IDDM $(p=0.003)$ and correlated with fasting glucose levels $(r=0.77)$. Nocturnal growth hormone $(\mathrm{GH})$ was increased fivefold in IDDM and correlated to nocturnal lipolysis $(r=0.83)$. Adipose tissue blood flow increased during the night in a similar fashion in both groups. Nearnormalization of glucose for $24 \mathrm{~h}$ in IDDM did not affect the nocturnal increases in NEFA, GH and lipolysis. In conclusion, a circadian rhythm in lipolysis was found. Increased lipolytic rates during evening-night may at least in part raise nocturnal circulating NEFA. Nocturnal NEFA and lipolysis are further enhanced in IDDM, maybe due to elevated GH, but not to insulinopenia or hyperglycaemia. [Diabetologia (1997) 40: 1070-1078]

Keywords Microdialysis, glycerol, non-esterified fatty acids, circadian rhythm, growth hormone.
Although insulin-dependent diabetes mellitus (IDDM) is accompanied by several metabolic abnormalities [1], metabolic control in clinical practice is focused on glycaemic control. Insulin influences the circulating non-esterified fatty acids (NEFA) via its antilipolytic action in adipose tissue. Circulating NEFA are elevated in untreated IDDM, a finding attributed to insulinopenia [2-4]. Insulin therapy

Received: 27 February 1997 and in revised form: 28 April 1997

Corresponding author: J. Bolinder, M.D., Ph.D., Department of Medicine, M63, Huddinge Hospital, S-14186 Huddinge, Sweden

A bbreviations: IDDM, Insulin-dependent diabetes mellitus; NEFA, non-esterified fatty acids; $\mathrm{GH}$, growth hormone; $\mathrm{CV}$, coefficient of variation; AUC, area under the curve; ANOVA, analysis of variance. normalizes plasma NEFA [4-6], at least during the day. In normal and IDDM subjects NEFA increase at night [7-9]. The mechanisms underlying this and the influence of IDDM are not understood. Growth hormone $(\mathrm{GH})$ may be involved, since it regulates nocturnal lipolysis $[8,10]$ and is elevated in IDDM $[4,11,12]$. An increase in NEFA may lead to a number of abnormalities, as discussed in detail elsewhere [13]. In many cases blood glucose levels are poorly controlled at night in IDDM [14]. This might also be influenced by NEFA, which compete with glucose in muscle metabolism and stimulate liver gluconeogenesis [15].

It is possible to monitor continuously the lipolysis end-product glycerol in adipose tissue with microdialysis $[16,17]$. Small microdialysis tubes are placed in the interstitial space of subcutaneous adipose tissue and slowly perfused with a neutral solvent. The 
Table 1. Clinical characteristics of patients and healthy control subjects

\begin{tabular}{llll}
\hline & IDDM & IDDM re-investigated & Control subjects \\
\hline Sex $($ male/female) & $5 / 5$ & $3 / 4$ & $3 / 5$ \\
Age $($ years $)$ & $31 \pm 2(20-49)$ & $33 \pm 3(23-49)$ & $41 \pm 4(28-66)$ \\
BMI $\left(\mathrm{kg} / \mathrm{m}^{2}\right)$ & $23.3 \pm 0.5$ & $23.4 \pm 0.6$ & $(1.9 \pm 1.0$ \\
& $(20.4-24.8)$ & $(20.4-24.8)$ & $22 \pm 4(10-36)$ \\
Diabetes duration $($ years $)$ & $22 \pm 3(8-36)$ & $0.6 \pm 0.07(0.4-1.0)$ \\
Insulin dose $(\mathrm{IU} / \mathrm{kg} \times 24 \mathrm{~h})$ & $0.7 \pm 0.05(0.4-1.0)$ & $7.6 \pm 0.3(6.1-8.8)$ \\
$\mathrm{HbA}_{1 \mathrm{c}}(\%)^{\mathrm{a}}$ & $7.6 \pm 0.2(6.1-8.8)$ & & \\
\hline
\end{tabular}

Mean \pm SEM. Range in parentheses

${ }^{\mathrm{a}} \mathrm{HbA}_{1 \mathrm{c}}$ normal range $3.5-5 \%$

outgoing dialysate will reflect the composition of the interstitial fluid due to the diffusion of substances across the dialysis membrane. The microdialysis technique can also be used over a long period of time for continuous monitoring of the true metabolite concentration in the interstitial space of subcutaneous adipose tissue in ambulatory IDDM patients [18] and the variations in adipose tissue blood flow [19]. The latter is important for lipolysis since the local blood flow rate may influence the mobilization of lipids from adipose tissue [20]. Using microdialysis, in this study we have monitored the circadian adipose tissue glycerol and blood flow variations (lipolysis index) during ambulatory conditions in control and IDDM subjects and compared them to the circulating NEFA.

\section{Subjects and methods}

Subjects. Ten non-obese patients with IDDM and eight agematched, non-obese, drug-free healthy subjects were studied (Table 1). Background retinopathy in nine patients and microalbuminuria in one were the only evident major diabetic complications. All patients received multiple insulin injection therapy (4-5 doses). They were otherwise healthy and took no other medication. The study was approved by the ethics committee at Huddinge Hospital. Informed consent was obtained.

M icrodialysis device. The microdialysis catheter has been described in detail previously [21]. Briefly, a semi-permeable membrane $(30 \times 0.62 \mathrm{~mm}$, molecular cut-off $20000 \mathrm{kDa})$ is glued to the end of a double-lumen cannula. The perfusion fluid enters the device through the outer cannula, streams down to the microdialysis membrane and leaves through an inner cannula, from which it is collected. An exchange of substances in the extracellular fluid takes place over the membrane [16].

Study protocol. The study started at 07.30 hours on day 1 . The subjects had breakfast and took morning insulin at home. A cubital vein catheter was inserted for blood sampling. Two microdialysis catheters were introduced percutaneously into the periumbilical subcutaneous adipose tissue and continuously perfused with sterile Ringer's solution [22] alone or with the addition of ethanol $(50 \mathrm{mmol} / \mathrm{l})$. Portable microinfusion pumps (MiniMed 504; Minimed Technologies, Sylmar, Calif., USA) at flow rates of $0.5 \mu \mathrm{l} / \mathrm{min}$ (Ringer catheter) and $5 \mu \mathrm{l} / \mathrm{min}$ (Ringer-ethanol catheter) were used. Fractions of dialysate were sampled for the analyses of glucose, glycerol and ethanol (1-h samples from 08.00 hours to 21.00 hours and 2-h samples during the night in order to permit the subjects to sleep, despite sampling). The ratio of ethanol in the outgoing vs the ingoing solvent was calculated for the ethanol-Ringer catheter and reflects indirectly qualitative variations in adipose tissue blood flow [23]. Previous investigations have directly compared the microdialysis and Xenon techniques to measure blood flow variations in adipose tissue; an excellent correlation was observed [24].

Glucose, glycerol and NEFA were determined in venous blood obtained in the middle of each dialysate sampling period. Nighttime concentrations of plasma GH and serum free immunoreactive insulin were determined in the seven patients who were re-investigated (see below) with an intravenous insulin infusion and in six control subjects.

The study conditions were standardized for meals and snacks: lunch at 11.30 hours, afternoon snack at 14.00 hours, dinner at 16.30 hours, evening snack at 19.00 hours and breakfast day 2 at 07.30 hours. The portable pumps allowed the subjects to move freely between the sampling times, but physical activity was restricted to short walks inside the hospital. All subjects were at rest in bed from 22.00 hours and slept through the night.

Seven of the IDDM patients with clinical characteristics similar to those in the whole group (Table 1) were re-investigated 2-6 months after the first study. All had stable body weight and had remained at their previous level of physical activity. The patients reported to the diabetes unit at 20.00 hours on the day before the study. They received a variable intravenous insulin infusion (Actrapid; Novo Nordisk, Copenhagen, Denmark) which was adjusted to achieve euglycaemia (5$7 \mathrm{mmol} / \mathrm{l}$ ). The microdialysis catheters and the venous plasma cannula were inserted and sampling and schedule for physical activity, meals and sleep were performed exactly as described above. According to the results of frequent venous blood glucose analyses (HemoCue; HemoCue AB, Ängelholm, Sweden) the intravenous insulin infusion was varied to obtain sustained circadian normoglycaemia throughout the study period. Hypoglycaemia was avoided in all patients.

Separate experiments were performed to calculate the adipose tissue interstitial glycerol recovery using $1{ }^{14}$-C glycerol [25]. The fluxes of endogenous and isotopic glycerol over the membrane were assumed to be equal. Three healthy, normalweight subjects were microdialysed with Ringer's solution, supplemented with $1500 \mathrm{cpm} / \mu \mathrm{l}$ of $1{ }^{14}{ }^{14}$ C glycerol (Amersham Sweden AB, Solna, Sweden). Dialysate was sampled in 45-min fractions during $270 \mathrm{~min}$. The recovery (in \%) was calculated as

$\frac{100 \times\left(\mathrm{cpm}_{\text {in }}-\mathrm{cpm}_{\text {out }}\right)}{\mathrm{cpm}_{\text {in. }}}$ 
where $\mathrm{cpm}_{\text {in }}$ is the radioactivity in the ingoing perfusate and $\mathrm{cpm}_{\text {out }}$ is the radioactivity in the dialysate.

Chemical analyses. Plasma and dialysate glucose concentrations were determined by a glucose oxidase method [26] (coefficient of variation (CV) $5 \%$ for both). The dialysate glycerol concentration was assessed by a commercial colorimetric method (Randox Laboratories Ltd, Ardmore, UK) (CV $5 \%$ ). The intraindividual $\mathrm{CV}$ for adipose tissue dialysate glycerol sampled with microdialysis was $6 \pm 2 \%$ in previous experiments [27]. Plasma glycerol was determined by bioluminescence [28] $(\mathrm{CV}<3.7 \%)$, NEFA by an enzymatic colorimetric test-kit (Wako Chemicals, GmbH, Neuss, Germany) $(\mathrm{CV}<2.7 \%)$, and ethanol by an enzymatic, fluorometric method [29] (CV 2\%). Free insulin in serum was determined by a radioimmunoassay kit (Pharmacia, Uppsala, Sweden) after precipitation with polyethylene glycol. The lower limit of the assay was $12 \mathrm{pmol} / \mathrm{l}$ (all samples in subjects and patients were above this limit) and the CV was less than $6 \%$. Plasma $\mathrm{GH}$ was analysed by a commercial fluoroimmunoassay, Delfia (Wallac Oy, Turku, Finland), using international reference standard $80 / 505$ and the CV was $6.7 \%$.

Statistical analysis. The circadian variations were evaluated by analysis of variance corrected for repeated measurements (ANOVA) for comparison throughout the circadian profiles, using one- or two-factor analysis, respectively, for comparison within the group or between the groups. Data were analysed at the following time intervals: 09.00 hours -20.00 hours (day/ diurnal), 20.00 hours - 08.00 hours (night/nocturnal), and 09.00 hours -08.00 hours (circadian) unless stated otherwise. The area under the curve (AUC) was calculated by a trapezoidal method. Mean values and AUCs were compared using the Student's unpaired or paired t-test, when applicable. The respective increase in NEFA and dialysate glycerol during the afternoon was compared with Wilcoxon's signed rank-test. The GH concentrations were compared using the Mann-Whitney rank-test for non-paired values because the concentrations were not normally distributed. Linear correlation analysis by the method of least square was performed. Values are expressed as means \pm SEM.

\section{Results}

Findings with metabolites. The circadian plasma glucose profiles for the two groups are shown in Figure 1A. Glucose was increased in the IDDM patients during the day and there was a further rise in glucose concentrations during the night in IDDM (one-factor ANOVA $F=1,8, p=0.03$ ). The concentrations of dialysate glucose were almost identical with the respective plasma concentrations throughout the experimental period in both groups (dialysate concentrations not shown). The tissue dialysate glucose concentration was $92 \pm 3 \%$ of the respective plasma concentration confirming earlier results $[18,22]$ and indicating a complete or near-complete recovery of glucose in the dialysate.

Dialysate glycerol concentrations, are shown in Figure 1B. The mean calculated rate of recovery of glycerol obtained from the isotope experiments was $94.5 \pm 2.6 \%$, indicating almost complete recovery.
A

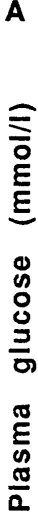
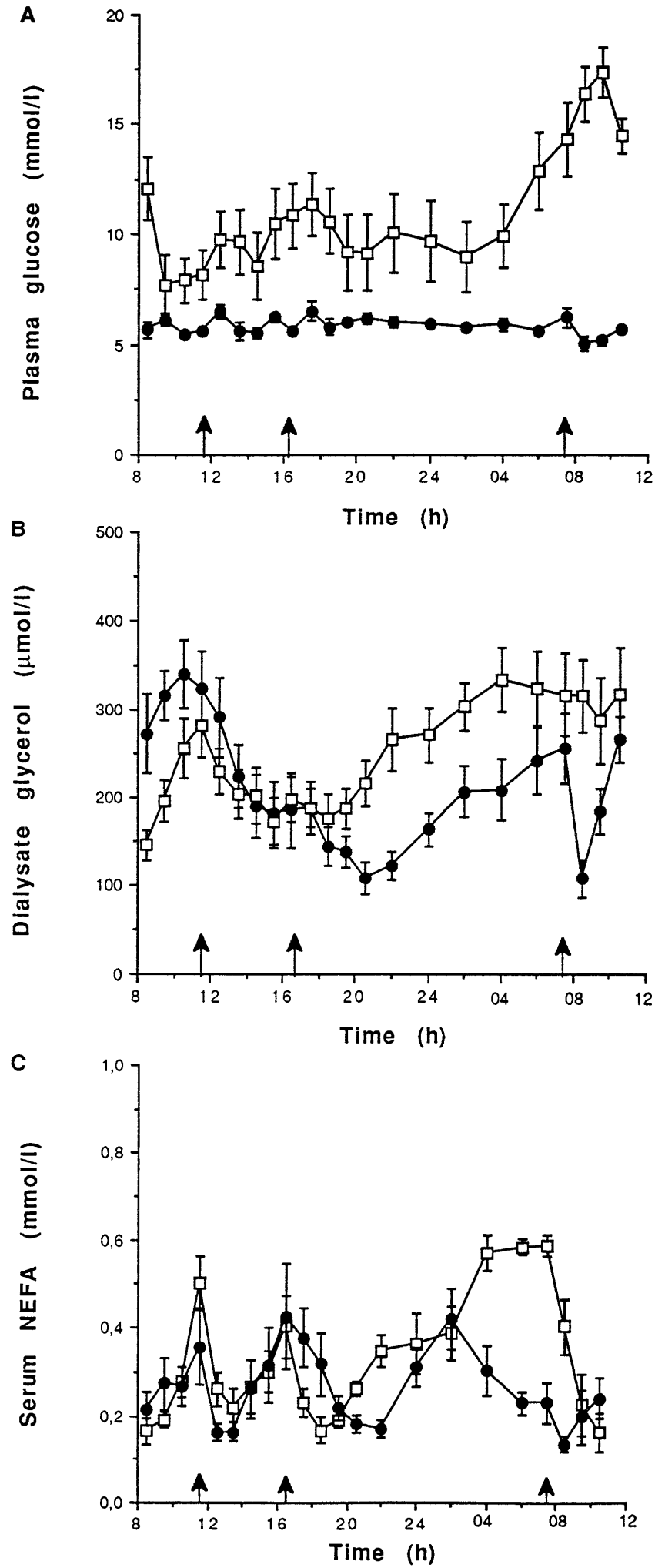

Fig. 1A -C. Circadian variations in plasma glucose, dialysate glycerol and serum NEFA. Microdialysis catheters were inserted in the abdominal subcutaneous tissue and were continuously perfused. Dialysate was sampled in 1-2 $\mathrm{h}$ fractions for the analysis of glucose (not shown) and glycerol. Blood sampling was performed in the middle of each dialysate fraction. The circulating glucose (A), dialysate glycerol (B) and serum NEFA (C) is shown. Values are mean \pm SEM in 10 IDDM patients $(\square)$ and 8 healthy controls $(\mathbf{O})$. Arrows indicate meals 
The tissue dialysate glycerol in both groups decreased from noon to a nadir at 20.30 hours in the healthy control subjects and at 18.30 hours in the IDDM group. Thereafter, a gradual increase in the tissue glycerol was observed throughout the night. This circadian pattern differed significantly between the two groups $(F=7,2, p=0.0001$ by two-factor ANOVA). Dialysate glycerol began to increase earlier in the evening in IDDM as compared with the control state. The mean nocturnal tissue dialysate glycerol concentrations were higher in IDDM $(277 \pm 30 \mu \mathrm{mol} / \mathrm{l})$ than in the control state $(181 \pm 24 \mu \mathrm{mol} / \mathrm{l} ; \quad \mathrm{t}=2.4$, $p=0.03$ ). However, the mean diurnal dialysate glycerol concentrations were similar in the two groups (IDDM $211 \pm 25$ vs control $238 \pm 31 \mu \mathrm{mol} / 1, \mathrm{t}=0.7$, $p=0.49)$. The plasma concentrations were one third to one sixth of the concentrations in the tissue dialysate confirming earlier results of microdialysis [27, $30,31]$. Increased nocturnal plasma glycerol levels were found in the IDDM patients but there was no difference between the groups during the day (twofactor ANOVA 20.00-08.00 hours $F=2,6, p=0.02$, 09.00-20.00 hours $F=0.52, p=0.88$ ).

The circadian patterns of circulating NEFA are shown in Figure 1C. During the day there were distinct preprandial increases and postprandial decreases in the concentrations of NEFA, which were similar in both groups (two-way ANOVA 09.00-20.00 hours $F=1.99, p=0.04)$. The daytime NEFA pattern differed from the respective pattern of dialysate glycerol; in the afternoon (13.30-16.30 hours) the relative increase in circulating NEFA concentrations was larger than the respective change in dialysate glycerol concentrations (IDDM: NEFA $75 \pm 31 \%$ vs dialysate glycerol $7 \pm 14 \%, p=0.02$, control subjects: NEFA $154 \pm 64 \%$ vs dialysate glycerol $-21 \pm 9 \%, p=0.02$ ). The diurnal mean level of NEFA or the area under the NEFA diurnal curve did not differ significantly between the groups (values not shown). However, there were pronounced differences in nocturnal NEFA. In the IDDM group, NEFA increased continuously during the night whereas in the control group, NEFA peaked at 02.00 hours and then gradually decreased (two-factor ANOVA 20.00-08.00 hours $F=3.71, p=0.003)$. The night-time mean NEFA was $0.41 \pm 0.05$ in IDDM vs $0.26 \pm 0.03 \mathrm{mmol} / 1$ in control subjects $(\mathrm{t}=2.44, \mathrm{p}=0.03)$. A similar difference was observed in night-time AUC for NEFA. The nighttime AUC for NEFA and the dialysate glycerol were positively correlated in IDDM $(r=0.75, p=0.02)$. The concentrations of the fasting NEFA and the AUC of night-time NEFA correlated positively to the concentrations of the fasting plasma glucose in IDDM $(r=0.77, p=0.01$ and $0.75, p=0.01$, respectively). No significant correlations between these measures were found in the control group.

In order to investigate the role of glucose control on lipolysis in IDDM the patients were divided into two groups on the basis of $\mathrm{HbA}_{1 \mathrm{c}}$ (figure not shown). The dialysate glycerol concentrations did not differ between the patients with poor or average glycaemic control $\left(\mathrm{HbA}_{1 \mathrm{c}}>7.6 \%, \mathrm{n}=6\right)$ and those with good glycaemic control $\left(\mathrm{HbA}_{1 \mathrm{c}}<7.6 \%, \mathrm{n}=4\right)$ (ANOVA 2-factor repeated measurement $F=1,3$, $p=0,2)$. Also the insulin requirements were similar in these two groups $(0.72 \pm 0.06$ vs $0.63 \pm 0.20 \mathrm{IU} /$ $\mathrm{kg}, \mathrm{t}=0.8, \mathrm{p}=0.5)$. Age and diabetes duration did not differ significantly between the groups (data not shown).

Seven IDDM patients were re-investigated during a 24-h intravenous insulin infusion (Fig. 2). The metabolic profiles in the first and second investigations were compared. With the intravenous insulin infusion, a marked improvement in the circadian glucose profile was achieved (circadian two-factor ANOVA $\mathrm{F}=2.7, \mathrm{p}=0.0005$ ) and the nocturnal hyperglycaemia observed in the first study was avoided (nighttime two-way ANOVA $F=5.6, p=0.0001$ ). Plasma glucose is shown in Figure $2 \mathrm{~A}$, glucose values during intravenous insulin infusion were kept at 5.9$8.0 \mathrm{mmol} / \mathrm{l}$. Similar results were obtained with dialysate glucose (figure not shown).

However, there was no significant difference in the overall dialysate glycerol pattern between the two investigations (circadian two-factor ANOVA $F=1.02$, $p=0.4$ ). Nor were there any significant differences in the dialysate glycerol between the two investigations when day- and night-time values were investigated separately. The circulating glycerol concentrations were also not affected by the intravenous insulin infusion (data not shown). Intravenous insulin administration lowered the concentrations of circulating NEFA during the daytime, as compared to the first study (two-factor ANOVA F-test 3.23, $p=0.003)$. However, the night-time concentrations of NEFA were not affected by intravenous insulin (two-factor ANOVA $F=0.69, p=0.66$; Fig. 2C). Lastly, compared to control subjects mean nocturnal NEFA levels were still increased in the IDDM patients receiving intravenous insulin $(0.26 \pm 0.03$ vs $0.34 \pm 0.02 \mathrm{mmol} / \mathrm{l}, \mathrm{t}=2.54, \mathrm{p}=0.025)$.

Findings with blood flow. Figure 3 shows the dialysate ethanol outflow/inflow ratio. In both groups, a significant decrease in the ratio, indicating an increased ethanol escape (blood flow) was observed during the night (circadian one-factor ANOVA control group $F=2.66, \quad p=0,002, \quad$ IDDM group $F=4.92$, $p=0.0001$; this did not differ between the two groups ( $F=0.71, p=0.79$ by two-factor ANOVA) (Fig. 3A). In the re-investigated IDDM patients, the ethanol escape increased markedly during the day (09.0020.00 hours) when insulin was given intravenously, as judged by the reduction in the ethanol outflow/inflow ratio (mean ethanol ratio daytime, intravenous insulin $0.57 \pm 0.03$ vs subcutaneous insulin $0.70 \pm 0.03$, 


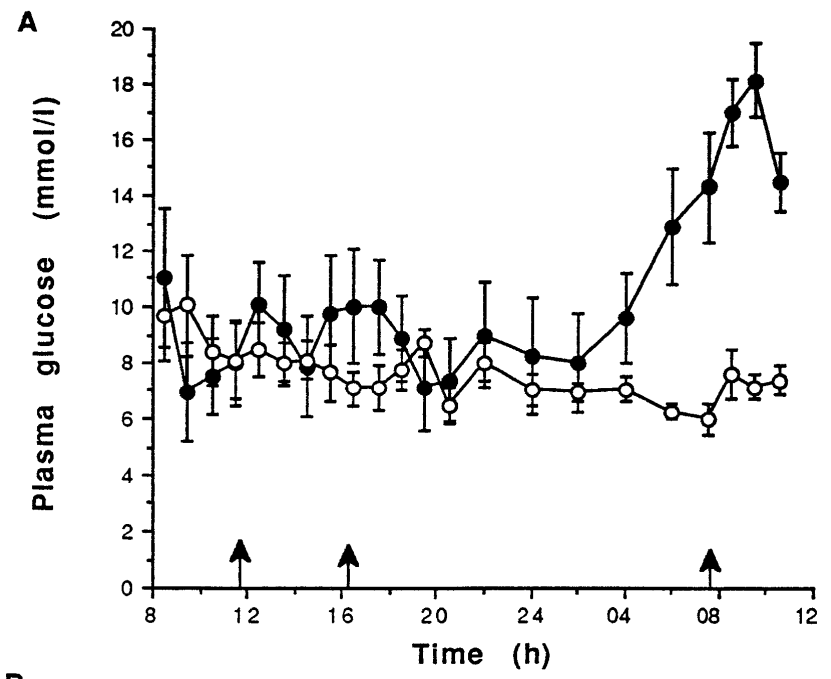

B
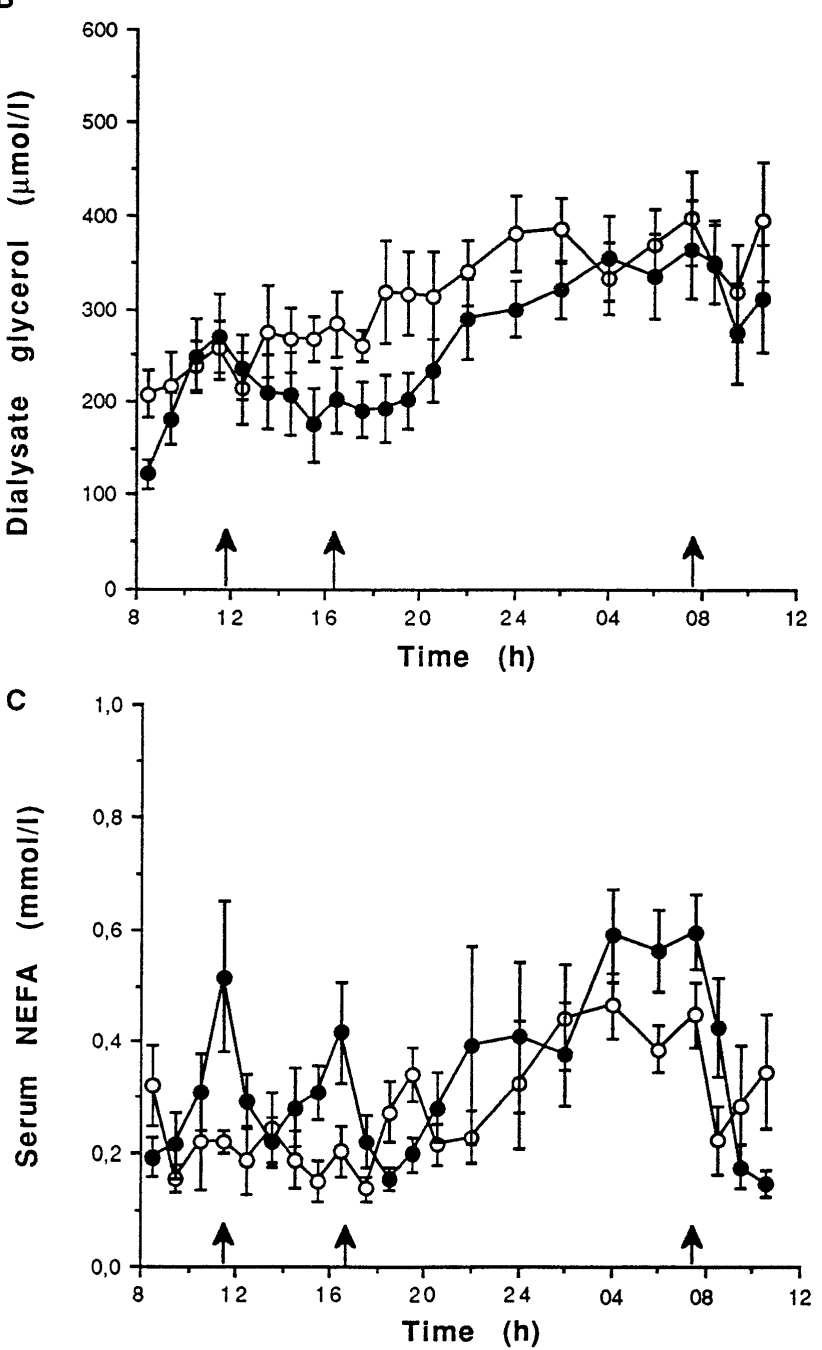

Fig. 2A - C. Circadian patterns of venous plasma glucose (A), adipose tissue glycerol (B) and serum concentrations of NEFA (C) are presented in seven IDDM patients receiving their regular s.c. insulin regimen $(\mathbf{O})$ or a variable intravenous insulin infusion when re-investigated $(\bigcirc)$. Microdialysis sampling was performed as described in the legend to Figure 1

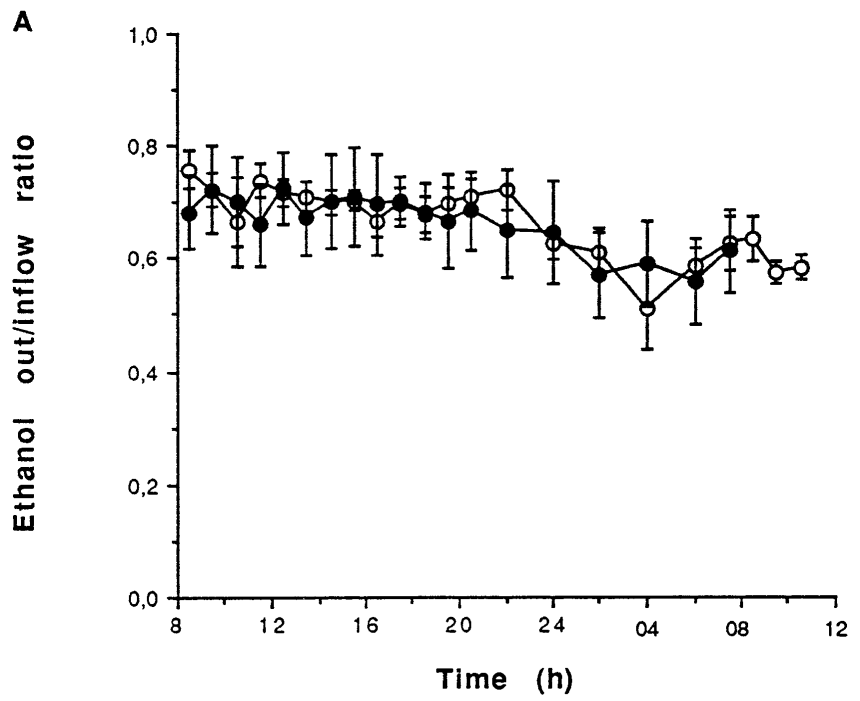

B

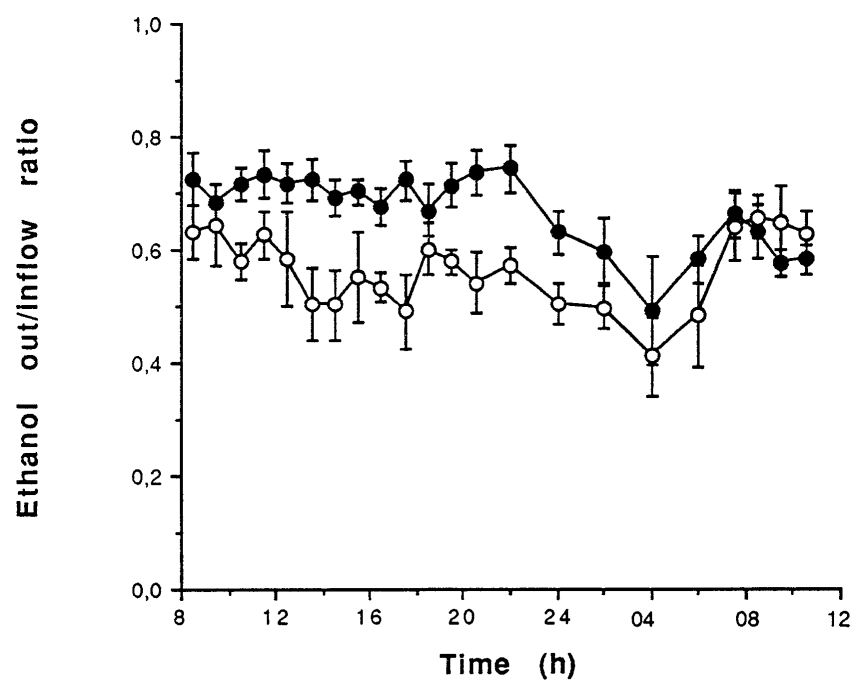

Fig. 3A , B. Circadian variations in the ethanol escape in patients with IDDM $(\bigcirc)$ and healthy control subjects $(\bigcirc)$. Microdialysis sampling was performed as described in the legend to Figure 1 and the ethanol outflow/inflow ratio in all of the IDDM patients and in six of the control subjects is presented in A. The dialysis solvent was supplied with ethanol (50 $\mathrm{mmol} / \mathrm{l})$. Changes in the outflow/inflow ratio reflect variations in the local blood flow. Post-hoc analysis of the one-way ANOVA revealed a significant difference $(p<0.05)$ between the time intervals $09.00-20.00$ hours and $03.00-07.00$ hours in the IDDM patients and from 09.00-23.00 hours and 01.0007.00 hours in the control group. In $\mathbf{B}$, the circadian pattern of the ethanol outflow/inflow ratio in response to intravenous insulin $(\bigcirc)$ or s. c. insulin $(O)$ is shown $(n=7)$

$\mathrm{t}=5.54, \mathrm{p}=0.002$; Fig. 3B). The night-time decrease in ethanol ratio was maintained when insulin was administered intravenously (one-factor ANOVA intravenous insulin $F=1.96, p=0.03$ ). The mean nighttime ethanol ratios in the two investigations did not differ significantly (intravenous insulin $0.52 \pm 0.03$ vs subcutaneous insulin $0.64 \pm 0.04, p=0.07$ ). 
Findings with hormones. The free insulin concentrations in serum and plasma $\mathrm{GH}$ concentrations are shown in Figure 4. IDDM patients on subcutaneous insulin had lower free insulin concentrations than the control subjects in the early night hours, but the concentrations were normalized with intravenous insulin. GH concentrations were higher in the IDDM patients from $20.30-02.00$ hours. $(p=0.005-0.04)$, than in the control subjects. This difference remained when insulin was given intravenously. In IDDM patients, the mean nocturnal GH (20.30-06.00 hours) correlated to the corresponding mean nocturnal dialysate glycerol $(r=0.83, p=0.04)$ but not to $\mathrm{HbA}_{1 \mathrm{c}}$ or fasting glucose concentration.

Comparison of findings at $08.00-11.00$ hours day 1 and 2. It is seen in Figure 1 that plasma glucose in diabetic subjects and dialysate glycerol in control and diabetic subjects had somewhat different kinetic profiles between 08.00 and 11.00 hours on days 1 and 2 . This is most likely due to different procedures at these two occasions. On day 1 all subjects arrived at the hospital in a non-standardized fashion except fasting overnight. On day 2 they were standardized as regards time in bed during the night, wake-up and breakfast.

\section{Discussion}

In the present study, adipose tissue lipolysis has been investigated in vivo under normal living conditions. This was done with a relatively new technique, microdialysis, which permits continuous monitoring of glycerol and blood flow variations in subcutaneous adipose tissue $[16,17]$. In theory, variations in glycerol in the interstitial space are determined by three major factors: local production, local utilization and removal by blood flow. Fat tissue has an insignificant re-utilization of glycerol. Thus, production by lipolysis and removal by blood flow are the only important factors controlling the level of glycerol in adipose tissue. The method used in this study determines only relative changes in lipolysis and blood flow. Alternative techniques exist for measuring true lipolysis and blood flow rates, such as isotope infusion or arteriovenous cannulation, in combination with Xenon clearance (for tissue blood flow). Unfortunately it is impossible to use such methods under present experimental conditions (ambulatory measurements for $24 \mathrm{~h})$.

Our study shows a distinct circadian rhythm of lipolysis, which is altered in IDDM. When data for adipose tissue glycerol and ethanol ratio are considered together, it appears that the lipolytic activity gradually declines during the day and increases at night. The pattern is different for circulating NEFA, which involves a distinct meal-suppression and preprandial
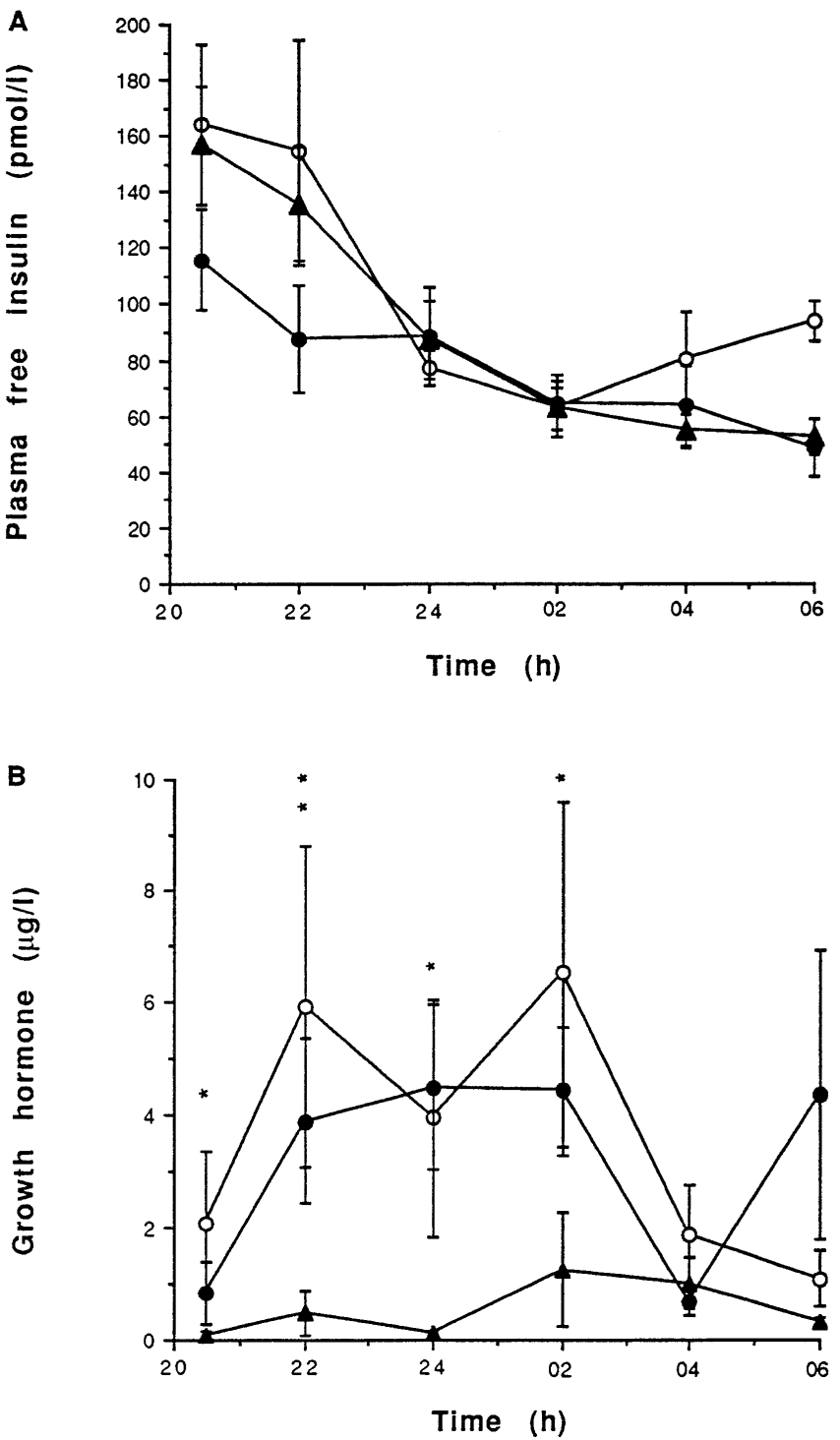

Fig. 4A, B. Nocturnal concentrations of free insulin $(\mathbf{A})$ and GH (B) in seven IDDM patients receiving their regular s. c. insulin regimen $(\mathbf{O})$ or a variable i.v. insulin infusion when re-investigated $(\bigcirc)$ and in six healthy control subjects $(\boldsymbol{A})$. (A) IDDM patients on s.c. insulin vs control subjects; ANOVA $F=4.1, p=0.003$. (B) $* p<0.05, * * p<0.01$ for differences in $\mathrm{GH}$ between IDDM patients on s.c. insulin and the control subjects

increase in the day and an increase during the night. If we assume that adipose tissue is the major delivery source of NEFA, it seems reasonable to suggest that several factors control the circulating NEFA level in the day, whereas adipose tissue lipolysis is a major determinant at night. It should be noted that only one subcutaneous adipose tissue depot was investigated. Large regional variations are known to exist between various subcutaneous fat depots and between subcutaneous and inner (i.e. visceral) fat depots [32]. Unfortunately, the latter adipose tissue region cannot be investigated in a clinical setting. However, NEFA release from the presently investigated adipose tissue 
region correlates strongly to mean arterial NEFA concentrations indicating that this fat depot is representative for the whole body [33]. Hence, regional variations may be of less importance than previously believed.

As noted by others [16, 30, 31], we found that the concentration of glycerol in adipose tissue was much higher than that in plasma. A gradual increase in adipose tissue blood flow occurred during the night, in accordance with findings in the subcutaneous tissue of the lower limb [34]. Increased blood flow accelerates removal of glycerol from the extracellular space of adipose tissue $[19,23]$. Whether the same is true for NEFA remains to be established. As discussed in detail [23], water-insoluble NEFA may be even more sensitive to changes in blood flow than water soluble glycerol. Local re-esterification of NEFA could also influence NEFA mobilization, besides lipolysis and blood flow, although a recent study has shown that re-esterification does not occur to a significant extent in the presently investigated major fat depot [33]. Thus, increased rates of nocturnal lipolysis and blood flow in subcutaneous adipose tissue could together be responsible for elevated concentrations at NEFA at night. A constant rate of glycerol turnover in vivo during the night has been demonstrated in healthy subjects $[9,10]$. Methodological factors may explain the divergence in results. Glycerol turnover in plasma indirectly measures the overall rate of lipolysis in all adipose tissue regions. We measured lipolysis directly in the major fat depot (abdominal subcutaneous fat).

Of clear clinical significance is the observation that the circadian lipolytic rhythm was markedly altered in IDDM. Although adipose glycerol concentrations and circulating NEFA concentrations were normal during the day, they were markedly elevated between 20.00 hours and 08.00 hours, which is half of the circadian period. Plasma glycerol was also elevated during the evening-night in IDDM. Since there was no significant difference between control and IDDM subjects in the nocturnal relative increase in the adipose tissue blood flow, it is likely that the increase in the rate of adipose lipolysis to some extent explains the evening and nocturnal increases in circulating NEFA in IDDM. However, other changes in NEFA turnover (e.g. the degree of re-esterification and regional variations in adipose tissue lipolysis) may also contribute since the night-time pattern of NEFA (but not of adipose tissue glycerol) differed between control and IDDM subjects. It seems unlikely that the microdialysis method fails to detect rapid changes in tissue glycerol. Previous experiments (exercise, insulin infusions) have shown an excellent correlation between temporal changes in adipose tissue and plasma glycerol $[27,35,36]$.

The above findings clearly emphasize the importance of studying IDDM patients not only during the day. Normal lipolysis rates and circulating NEFA concentrations in adequately controlled IDDM patients have been demonstrated in the daytime $[5,6]$. Our patients, who also were fairly well controlled, also had normal values during the first half of the day.

An elevation in the circulating NEFA at night may impair glucose metabolism, through mechanisms discussed earlier in this paper. Indeed, we found a strong correlation $(r=0.8)$ between the fasting and nighttime concentrations of NEFA and the fasting glucose concentrations in the IDDM subjects. This indicates that the nocturnal rise in NEFA could be partly responsible for the early morning hyperglycaemia. A strong temporal relationship between plasma NEFA levels and hepatic glucose output has previously been shown [37] as well as a reduction of nocturnal glucose production after pharmacological NEFA suppression [38].

Are disturbed lipolysis and NEFA levels at night in IDDM due to low insulin concentrations or hyperglycaemia? The fact that dialysate glycerol began to increase earlier in the evening in the IDDM patients as compared with control subjects (Fig.1) strongly suggests this. However most of the other data in this study argues against a role for insulin and glucose. Similar results were obtained if subjects with good $\left(\mathrm{HbA}_{1 \mathrm{c}}<7.6 \%\right)$ and average or poor $\left(\mathrm{HbA}_{1 \mathrm{c}}>7.6 \%\right)$ glucose control were compared (although some caution must be exercised regarding this finding, since the number of subjects was small). Furthermore, the concentrations of free insulin in serum were normal late at night (they were slightly decreased in the evening). More important, nocturnal adipose tissue glycerol and circulating NEFA concentrations did not normalize during the $24 \mathrm{~h}$ of intravenous insulin infusion, which almost completely normalized the blood glucose and circulating insulin concentrations both day and night. The presently obtained circulating insulin concentrations should induce complete suppression of lipolysis, which is known to occur at insulin concentrations lower than those needed to influence glucose metabolism [39]. As regards the adipose tissue blood flow, the data are somewhat difficult to interpret since the overall ethanol ratio was decreased in the daytime during the insulin infusion. In spite of this, the adipose tissue concentrations of glycerol during the evening and night remained significantly elevated during the insulin infusion and a nocturnal increase in the relative blood flow measurement was maintained. We therefore conclude that insulinopenia or hyperglycaemia are not responsible for the abnormal nocturnal lipolysis in IDDM.

What causes the circadian rhythm in lipolysis and why does it change in IDDM? The present study was not designed to answer this question. However, there may be several causes. Growth hormone can regulate lipolysis and glucose levels at night $[10,14]$. Thus, the elevated growth hormone concentration observed 
during the night in IDDM might further increase the nocturnal lipolytic rate and cause hyperglycaemia at night. Increased concentrations of $\mathrm{GH}$ are present in poorly controlled IDDM patients $[40,41]$ and intensive insulin treatment may correct some [42, 43], but not all [11] abnormalities in GH secretion. Our patients were fairly well controlled and a 24-h insulin infusion failed to normalize nocturnal GH. It is quite possible that longer periods of insulin infusion might be needed to correct GH. GH-induced lipolysis does not account for the increased requirement for insulin late at night in GH-deficient IDDM patients [10]. In our IDDM patients, however, night-time GH, nocturnal lipolysis and fasting glucose were interrelated. This agrees with previously reported findings that when the nocturnal GH peak and the NEFA increase were abolished, in vivo glucose metabolism improved in IDDM [8]. Clearly, the relationship between lipolysis, GH and hyperglycaemia in IDDM must be investigated further, for example, by more frequent sampling of $\mathrm{GH}$ or investigations during longer periods than $24 \mathrm{~h}$ of near-normoglycaemia. Other factors affecting the lipolytic pattern could be the autonomic nervous system, which also shows a circadian rhythm [34], local substances, such as adenosine and prostaglandins, which influence lipolysis and circadian variations in the sensitivity of insulin [13].

In summary, this study shows a circadian rhythm in lipolysis under normal living conditions. An increased nocturnal rate of lipolysis may, at least in part, cause elevated circulating NEFA concentrations during the night. Night-time lipolysis and NEFA are further increased in IDDM. Since abnormally elevated NEFA may have several side effects, including hyperglycaemia, the present study shows the importance of including circadian variations in adipose tissue lipolysis when evaluating the metabolic control in IDDM patients. However, more direct methods should be developed for this purpose, allowing measurement of true lipolytic rates under ambulatory conditions.

A cknowledgements. This study was supported by the Swedish Medical Research Council (19X-01034 and 14X-3c5774), Swedish Medical Society, the Swedish Diabetes Association, Karolinska Institute, CMA Research AB, Nordic Insulin Foundation, Novo Nordisk Pharma and the Tore Nilson, Martin Rind, Söderberg, Bergvall and Trygg-Hansa foundations.

\section{References}

1. Taylor R, Agius L (1988) The biochemistry of diabetes. Biochem J 250: 625-640

2. Trevisan R, Nosadini R, Avogaro A et al. (1986) Type 1 diabetes is characterized by insulin resistance, not only with regard to glucose but also to lipid and amino acid metabolism. J Clin Endocrinol Metab 62: 1155-1162

3. Jensen M D, Caruso M , Heiling V, Miles J M (1989) Insulin regulation of lipolysis in nondiabetic and IDDM subjects. Diabetes 38: 1595-1601
4. Johansen K, Hansen AP (1971) Diurnal serum growth hormone levels in poorly and well-controlled juvenile diabetics. Diabetes 20: 239-245

5. Frayn KN, Coppack SW, Humphreys SM, Clark ML, Evans RD (1993) Periprandial regulation of lipid metabolism in insulin-treated diabetes mellitus. Metabolism 42: 504-510

6. Alberti KGMM, Dornhurst A, Rowe AS (1975) Metabolic rhythms in normal and diabetic man. Israel J Med Sci 11: 571-580

7. Schlierf G, Dorow E (1973) Circadian patterns of triglycerides, free fatty acids, blood sugar and insulin during carbohydrate induction in man and their modification by nocturnal suppression of lipolysis. J Clin Invest 52: 732-740

8. Davidson MB, Harris MD, Ziel FH, Rosenberg CS (1988) Suppression of sleep-induced growth hormone secretion by anticholinergic agent abolishes the dawn phenomenon. Diabetes 37: 166-171

9. Boyle PJ, Avogaro A, Smith Let al. (1992) Role of GH in regulating nocturnal rates of lipolysis and plasma mevalonate levels in normal and diabetic humans. Am J Physiol 263:E168-E172

10. Boyle P J, Avogaro A, Smith L, Shah SD, Cryer PE, Santiago JV (1992) Absence of the dawn phenomenon and abnormal lipolysis in type 1 (insulin-dependent) diabetic patients with chronic growth hormone deficiency. Diabetologia 35: 372-379

11. Miller JD, Wright NM, Lester SE ET et al. (1992) Spontaneous and stimulated growth hormone release in adolescents with type 1 diabetes mellitus: effects of metabolic control. J Clin Endocrinol Metab 75: 1087-1091

12. Press M, Tamborlane WV, Sherwin RS (1986) Effect of insulin on growth hormone-induced metabolic derangements in diabetes. Metabolism 35: 956-959

13. Frayn K N, Williams CM, Arner P (1995) Are increased plama non-esterified fatty acid concentrations a risk marker for coronary heart disease and other chronic diseases? Clin Sci 90: 243-253

14. Bolli GB, Periello GP, Fanelli CG, De Feo P (1993) Nocturnal blood glucose control in type 1 diabetes mellitus. Diabetes Care 16 (S3):71-89

15. Fanelli C, Calderone S, Epifano L et al. (1993) Demonstration of a critical role for free fatty acids in mediating counterregulatory stimulation of gluconeogenesis and suppression of glucose utilization in humans. J Clin Invest 92: $1617-1622$

16. Arner P, Bülow J (1993) Assessment of adipose tissue metabolism in man - comparison of Fick and microdialysis technique. Clin Sci 82: 247-256

17. Lafontan M, Arner P (1996) Application of in situ microdialysis to measure metabolic and vascular responses in adipose tissue. TiPS 17: 309-313

18. Bolinder J, Ungerstedt U, Arner P (1993) Long-term continuous glucose monitoring with microdialysis in ambulatory insulin-dependent diabetic patients. Lancet 342: 10801085

19. Enoksson S, Nordenström J, Bolinder J, Arner P (1995) Influence of local blood flow on glycerol levels in human adipose tissue. Int J Obesity 19: 350-354

20. Rosell S, Belfrage P (1979) Blood circulation in adipose tissue. Physiol Rev 59: 1078-1104

21. Tossman U, Ungerstedt U (1986) Microdialysis in the study of extracellular levels of amino acids in the rat brain. Acta Physiol Scand 128: 9-14

22. Bolinder J, Ungerstedt U, Arner P (1992) Microdialysis measurement of the absolute glucose concentration in subcutaneous adipose tissue allowing glucose monitoring in diabetic patients. Diabetologia 35: 1177-1180 
23. Galitsky J, Lafontan M, Nordenström J, Arner P (1993) Role of vascular alpha-2 adrenoceptors in regulating lipid mobilization from human adipose tissue. J Clin Invest 91: 1997-2003

24. Felländer G, Linde B, Bolinder J (1995) Evaluation of the microdialysis ethanol technique for monitoring of subcutaneous adipose tissue blood flow in humans. Int $\mathrm{J}$ Obesity 20: $220-226$

25. Jansson P-A, Veneman T, Nurjahan N, Gerich J (1994) An improved method to calculate adipose tissue interstitial substrate recovery for microdialysis studies. Life Sciences 54: 1621-1624

26. Kaddish A H, Little RL, Sternberg JC (1968) A new and rapid method for the determination of glucose by measurement of the rate of oxygen consumption. Clin Chem 14: 116-131

27. Arner P, Kriegholm E, Engfeldt P, Boliner J (1990) Adrenergic regulation of lipolysis in situ at rest and during exercise. J Clin Invest 85: 893-898

28. Hellmér J, Arner P, Lundin A (1989) Automatic luminometric kinetic assay of glycerol for lipolysis studies. Analyt Biochem 177: 132-137

29. Bernst E, Gutman J (1974) Determination of ethanol with alcohol dehydrogenase and NAD. In: Bergmeyer HU (ed) Methods of enzymatic analysis. Vol 3. Verlag Weinheim, pp.1499-1505

30. Jansson PA, Smith U, Lönnroth P (1992) Interstitial glycerol concentration measured by microdialysis in two subcutaneous regions in humans. Am J Physiol 258:E918-E922

31. Maggs D G, Jacob R, Rife F et al. (1995) Interstitial fluid concentrations of glycerol, glucose, and amino acids. J Clin Invest 96: 370-377

32. Kissebah A H, Vydelingum N, Murray R (1982) Relation of body fat distribution to metabolic complications of obesity. J Clin Endocrinol Metab 54: 254-260

33. Samra JS, Clark ML, Humphreys SM, Macdonald IA, Frayn KN (1996) Regulation of lipid metabolism in adipose tissue during early starvation. Am J Physiol 271:E541E546
34. Sindrup JH, Kastrup J, Jørgensen B, Bülow J, Lassen NE (1991) Nocturnal variations in subcutaneous blood flow rates in lower leg of normal human subjects. Am J Physiol 260:H480-H485

35. Hagström-Toft E, Arner P, Näslund B, Ungerstedt U, Bolinder J (1991) Effects of insulin deprivation and replacement on in vivo subcutaneous adipose tissue substrate metabolism in humans. Diabetes 40: 666-672

36. Hagström-Toft E, Bolinder J, Eriksson S, Arner P (1995) Role of phosphodiesterase III in the antilipolytic effect of insulin in vivo. Diabetes 44: 1170-1175

37. Rebrin K, Steil GM, Getty L, Bergman RN (1995) Free fatty acid as a link in the regulation of hepatic glucose output by peripheral insulin. Diabetes 44: 1038-1045

38. Fulcher GR, Walker M, Catalano C, Agius L, Alberti KGMM (1992) Metabolic effects of suppression of nonesterified fatty acid levels with acipimox in obese NIDDM subjects. Diabetes 41: 1400-1408

39. Schade DS, Eaton RP (1977) Dose-response to insulin in man: differential effects on glucose and ketone body regulation. J Clin Endocrinol Metab 44: 1038-1053

40. Horner J M, Kemp SF, Hintz RL (1981) Growth hormone and somatomedin in insulin diabetes mellitus. J Clin Endocrinol Metab 53: 1148-1153

41. Edge JA, Dunger DB, Matthews DR, Gilbert JP, Smith CP (1990) Increased overnight growth release in diabetic compared with normal adolescents. J Clin Endocrinol Metab 71: $1356-1362$

42. Tamborlane WV, Hintz RL, Bergman M, Genel M, Felig P, Scherwin RS (1981) Insulin infusion-pump treatment of diabetes. Influence of improved metabolic control on plasma somatomedin levels. New Engl J Med 305: 303-307

43. Tamborlane W V, Scherwin RS, Koivisto V, Hendler R, Genel M, Felig P (1979) Normalization of the growth hormone and catecholamine response to exercise in juvenileonset diabetic subjects treated with a portable insulin infusion pump. Diabetes 28: 785-788 